
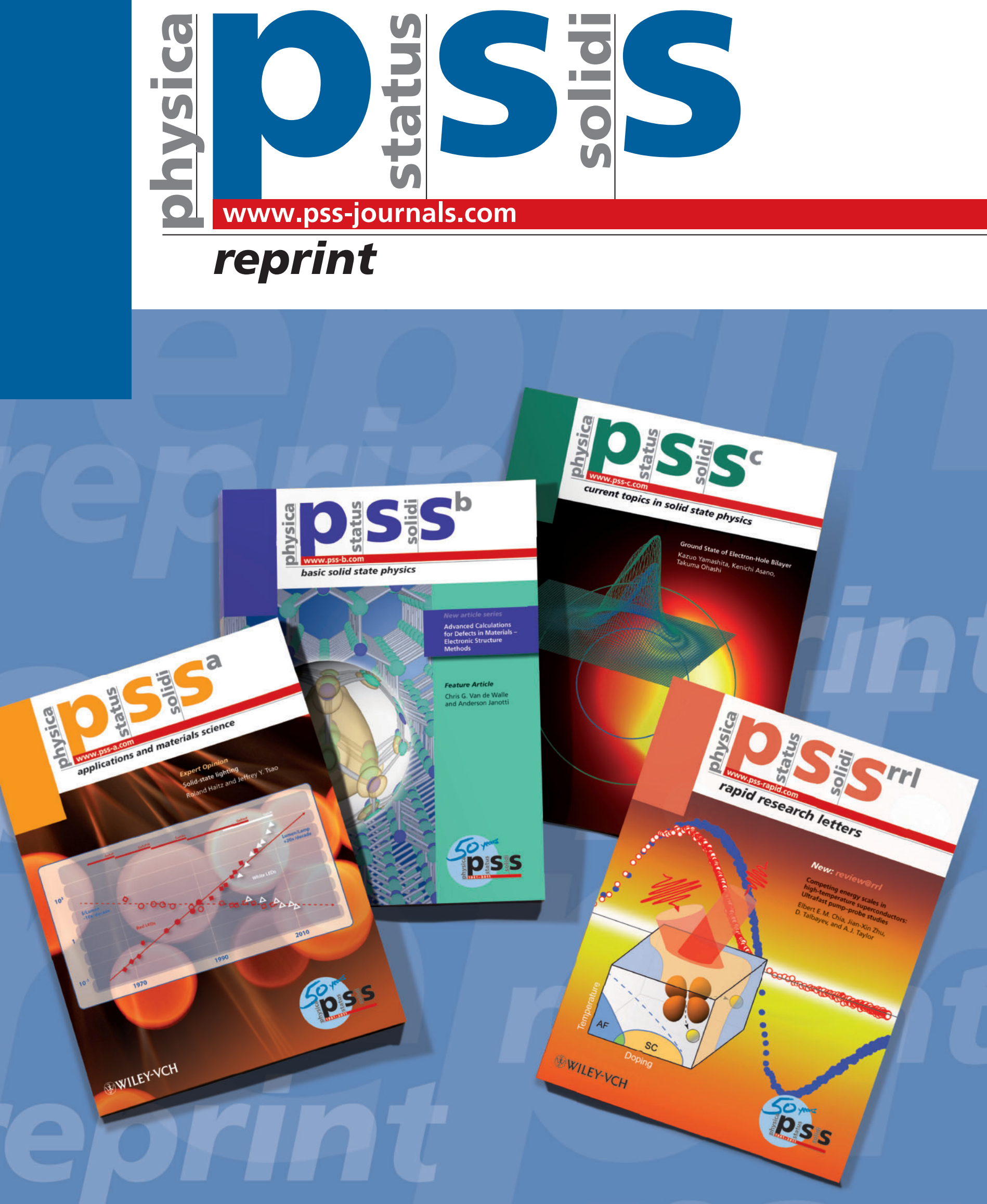




\title{
Raman investigation on thin and thick CdTe films obtained by close spaced vacuum sublimation technique
}

\author{
D. Nam ${ }^{1}$, H. Cheong ${ }^{1}$, A. S. Opanasyuk ${ }^{2}$, P. V. Koval ${ }^{*}$, V. V. Kosyak ${ }^{2}$, and P. M. Fochuk ${ }^{3}$ \\ ${ }^{1}$ Sogang University, 35, Baekbeom-ro, Mapo-gu, 121-742 Seoul, Korea \\ ${ }^{2}$ Sumy State University, 2, Rimsky-Korsakov str, Sumy 40007, Ukraine \\ ${ }^{3}$ Chernivtsi National University, 2, Kotsiubynskoho str., Chernivtsi 58012, Ukraine
}

Received 27 September 2013, revised 2 January 2014, accepted 11 March 2014

Published online 16 May 2014

Keywords thin and thick films, CdTe, structure, Raman spectroscopy

\footnotetext{
* Corresponding author: e-mail koval_p_sumdu@ukr.net
}

The CdTe thin and thick films were obtained by the close spaced vacuum sublimation technique on a glass substrate under the following growth conditions: the evaporator temperature was $620^{\circ} \mathrm{C}$; and the substrate temperature was varied in the range from $250{ }^{\circ} \mathrm{C}$ to $550{ }^{\circ} \mathrm{C}$. High purity CdTe powder was used as a charge for evaporation. The Raman spectra were measured using TRIAX 320 and TRIAX 550 spectrometers at room temperature. The 488-nm line and 514.5-nm line of an $\mathrm{Ar}^{+}$laser and a 785-nm diode laser were used as excitation sources. The signal was collected by the liquid nitrogen cooled chargecoupled-device (CCD) detector. A number of intense Raman peaks at 140,167,190,271, 332 and $493 \mathrm{~cm}^{-1}$ were observed and were interpreted as TO $\left(140 \mathrm{~cm}^{-1}\right)$, $1 \mathrm{LO}\left(167 \mathrm{~cm}^{-1}\right), 2 \mathrm{LO}\left(332 \mathrm{~cm}^{-1}\right), 3 \mathrm{LO}\left(493 \mathrm{~cm}^{-1}\right)$ phonon modes and plasmon-phonon mode $\left(190 \mathrm{~cm}^{-1}\right)$. The presence of several phonon replicas in the Raman spectra confirms high crystal quality of the samples.

\section{Introduction}

Due to its unique physical properties, CdTe is one of the most promising materials for the fabrication of semiconductor detectors of X-ray, $\gamma$-ray, and other types of nuclear radiation that can operate at room temperature. CdTedetectors $\left(\mathrm{Z}_{\mathrm{CdTe}} \sim 50\right)$ have significant advantages over detectors based on $\mathrm{Si}$ and GaAs and can be successfully used for the spectral analysis of the radiation in a wide range of energies. Energy resolution $R$ of monocrystalline CdTedetectors at room temperature reaches the following values: for spectral line $E=59.6 \mathrm{keV}$ of an ${ }^{241} \mathrm{Am}$ source, $R=$ $0.83 \mathrm{keV}$ and $R=1.2 \mathrm{keV}$ for the $E=662 \mathrm{keV}$ line of an ${ }^{137} \mathrm{Cs}$ source [1-3].

In order to reduce the cost of hard radiation detectors in recent years using thick (to 100 microns) structurally perfect epitaxial and polycrystalline films of cadmium telluride was suggested instead of using bulk single crystals [4-9]. Testing technology for base layers of instruments and detectors based on CdTe thick films has been studied by [10-12]. However, the possibility of using thin films of cadmium telluride layers to detect hard radiation has not been sufficiently investigated yet, and appropriate work to create a film detectors virtually absent.
Raman spectroscopy is a powerful method of studying the composition and quality of the crystal structure of semiconductor compounds. So far Raman spectra of bulk single crystals of CdTe have been mainly investigated. In contrast to this, the Raman spectra of polycrystalline cadmium telluride have been insufficiently studied and only discussed at [13-16]. Therefore, the study and comparison of Raman spectra of thin and thick CdTe films, obtained under different modes of deposition, are relevant.

\section{Experimental details}

Thin $(d=3-5 \mu \mathrm{m}$ thickness $)$ and thick $(d=80-100 \mu \mathrm{m}$ thickness) CdTe films were deposited from semiconductor purity powder on cleaned glass substrates by the CSVS method in a vacuum chamber under a residual gas pressure of about $6 \times 10^{-3} \mathrm{~Pa}$ [17]. To deposit CdTe films, we used various substrate temperatures, $T_{s}$, ranging from $250{ }^{\circ} \mathrm{C}$ to $550{ }^{\circ} \mathrm{C}$ and an evaporator temperature, $T_{e}$, of $620^{\circ} \mathrm{C}$. The deposition time was 5-30 minutes.

We studied the films' surface morphology by scanning electron microscopy (SEM). The average grain size $(D)$ 
was determined by the Jeffries method [18], while the thickness of the films was measured by the interference method and from SEM images of their cross-section.

The structural analysis of thin films was carried out with a DRON 4-07 X-ray diffractometer using a Ni-filtered $\mathrm{K}_{\alpha} \mathrm{Cu}$ radiation source in the range of diffraction angles $2 \theta$ from $20^{\circ}$ to $80^{\circ}$, where $2 \theta$ is the Bragg angle.

Phase analysis was undertaken via comparisons of the interplane distances and relative intensities of the films and the JCPDS reference data [19].

Raman spectra measurements were carried out at room temperature $\left(T=20^{\circ} \mathrm{C}\right)$ using Jobin-Yvon TRIAX 320 and TRIAX 550 spectrometers. An $\mathrm{Ar}^{+}$laser with the wavelengths of $\lambda=488 \mathrm{~nm}$ and $514.5 \mathrm{~nm}(50 \mathrm{~mW}$, TRIAX 320, TRIAX 550) and a 785-nm diode laser (3 mW, TRIAX 320) were used as excitation sources. The input slit width was $0.1 \mathrm{~mm}$. The resulting signal was detected using a liquid-nitrogen-cooled charge coupled device (CCD) detector. Each spectrum was acquired for 100 seconds (5 seconds, 20 times). Long-pass filters were used to eliminate Rayleigh scattering of light from the laser. Details of measuring Raman spectra and equipment used in this case are described in [20].

\section{Results and discussion}

Figures 1(a), (b) and (c) show the surface SEM image of CdTe-film. We determined that the growth mechanism of the films changes with increasing temperature. We observed the layer-by-layer growth of the fine-grained films obtained at a low substrate temperature $T_{s}<1 / 3 T_{m}$ (where $T_{m}=1092{ }^{\circ} \mathrm{C}$ is the melting point).

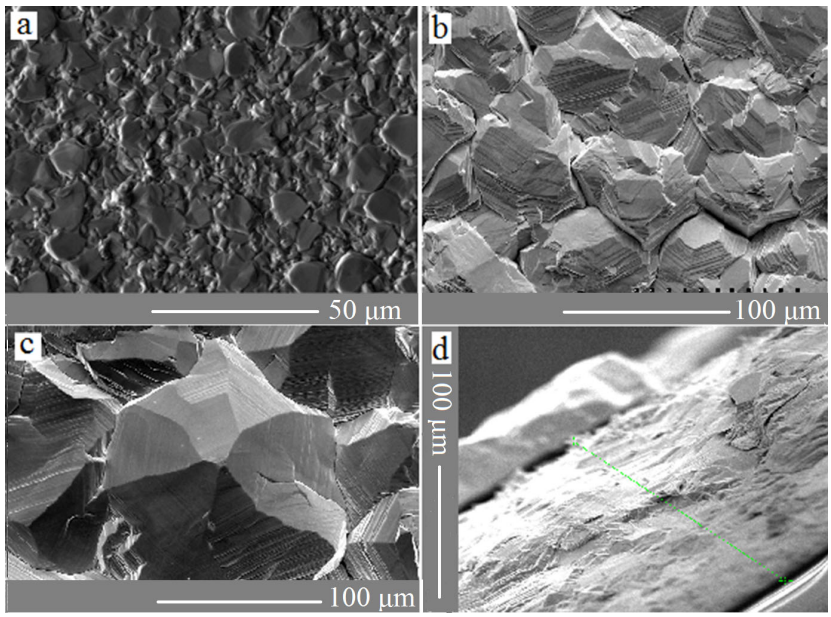

Figure 1 Surface SEM images of the thin CdTe films obtained at $T_{s}=550{ }^{\circ} \mathrm{C}(\mathrm{a})$; and thick at $T_{s}=400{ }^{\circ} \mathrm{C} \mathrm{(b);} T_{s}=550{ }^{\circ} \mathrm{C}(\mathrm{c})$; and cross-section film obtained at $T_{s}=550{ }^{\circ} \mathrm{C}$ (d)

In contrast, films obtained at higher substrate temperatures have a column-like structure; and the diameter of the columnar grains depends on the growth conditions and films' thickness $d$. Furthermore, the size of the grains $(D)$ increases with $T_{s}$ and $d$; for example, thin CdTe films obtained at $T_{e}=620{ }^{\circ} \mathrm{C}$ and $T_{s}=550{ }^{\circ} \mathrm{C}$ have a grain size $D$ $\approx 3-4 \mu \mathrm{m}$, thick $D \approx 70 \mu \mathrm{m}$ (Fig. 1(c)). More detailed growth mechanism and structural features of CdTe films are described in [21, 22].
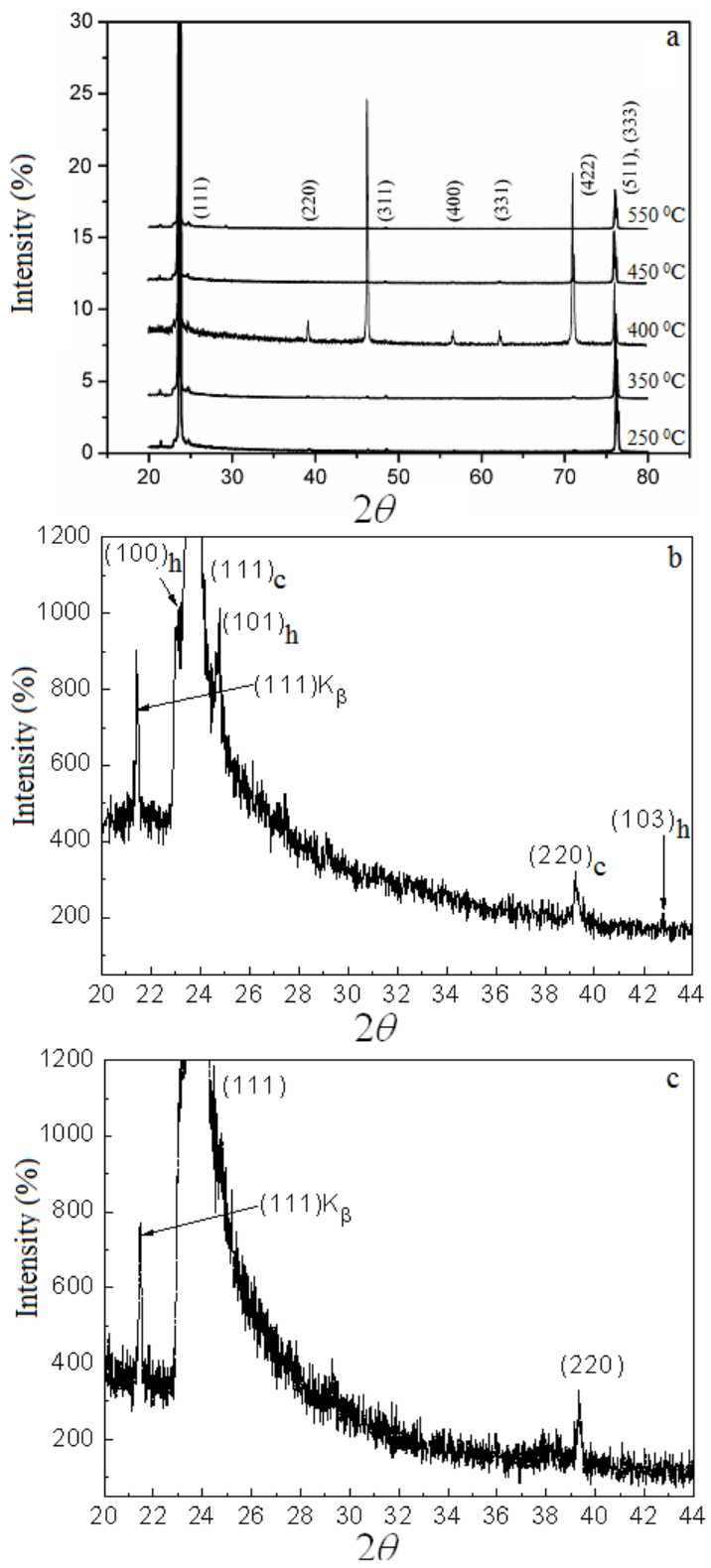

Figure 2 XRD patterns of the CdTe films: all (a); $T_{s}=250{ }^{\circ} \mathrm{C}$ (b) and $T_{s}=550{ }^{\circ} \mathrm{C}(\mathrm{c})$.

Diffraction patterns are shown in Fig. 2. Traces of the hexagonal phase were detected in films obtained at $T_{s}<$ $200-250{ }^{\circ} \mathrm{C}$ (peaks at $22.2^{\circ}-22.3^{\circ}-(100)_{\mathrm{h}}, 24.8^{\circ}-25.2^{\circ}-$ $(101)_{\mathrm{h}}$ and $\left.42.8^{\circ}-42.9^{\circ}-(103)_{\mathrm{h}}\right)$, Fig. 2b, whereas XRD patterns of the CdTe films deposited at higher substrate temperature $\left(T_{s}=300-550{ }^{\circ} \mathrm{C}\right)$ show only cubic single phase (see Fig. 2(c)). 
Figures 3-5 are the Raman spectra from the CdTe films, deposited under different conditions. Figure 3 shows the Raman spectra of thick CdTe samples grown at $350{ }^{\circ} \mathrm{C}-$ $550{ }^{\circ} \mathrm{C}$ measured with the 488 -nm excitation. In addition to the dominant $1 \mathrm{LO}$ at $167 \mathrm{~cm}^{-1}$, a $2 \mathrm{LO}$ signal is clearly seen [23]. The $3 \mathrm{LO}$ signal is not well resolved. The 1TO signal at $140 \mathrm{~cm}^{-1}$ is not observed due to the instrument limitation in low-frequency detection. For samples grown at higher temperatures, a peak at $271 \mathrm{~cm}^{-1}$ is also observed. Its origin is not clear: its frequency is close to that of $2 \mathrm{TO}$ $\left(280 \mathrm{~cm}^{-1}\right)$ [24], which may be enhanced due to the $E_{g}+\Delta$ resonance in CdTe $[25,26]$. This signal is not observed in Raman spectra measured with other excitation wavelengths. The origin of the broad feature around $222 \mathrm{~cm}^{-1}$ is not clear. The peak at $167 \mathrm{~cm}^{-1}$ frequency is asymmetric, which may be due to the superposition of another smaller peak intensity located at $190-200 \mathrm{~cm}^{-1}$ frequency, possibly a plasmon [27, 28].

Figure 4 shows the Raman spectra of CdTe films grown at $350{ }^{\circ} \mathrm{C}-550{ }^{\circ} \mathrm{C}$ for 15 or 30 min, measured with the excitation wavelength of $514.5 \mathrm{~nm}$. The $1 \mathrm{TO}, 1 \mathrm{LO}$, $2 \mathrm{LO}$, and $3 \mathrm{LO}$ signals are seen in all samples [23]. Figure 5 shows the resonant Raman spectra measured with the 785-nm excitation, which is close to the bandgap of CdTe at room temperature $(1.49 \mathrm{eV}, 832 \mathrm{~nm})$. The $\mathrm{LO}$ and its overtones are well resolved. The TO signal is not seen, probably due to different enhancement of LO and TO under resonant conditions. The strength of the higher-order LO phonons near resonance is often interpreted as an indication of the high quality of the samples $[25,26]$. The rising background in the spectra is due to the photoluminescence near the bandgap of CdTe.



Figure 3 Raman spectra of thick CdTe films deposited at different substrate temperatures $T_{\mathrm{s}}: 350{ }^{\circ} \mathrm{C}(1) ; 400{ }^{\circ} \mathrm{C}(2) ; 450{ }^{\circ} \mathrm{C}(3)$; $500{ }^{\circ} \mathrm{C}(4) ; 550{ }^{\circ} \mathrm{C}(5)$; (TRIAX $\left.320, \lambda=488 \mathrm{~nm}\right)$.

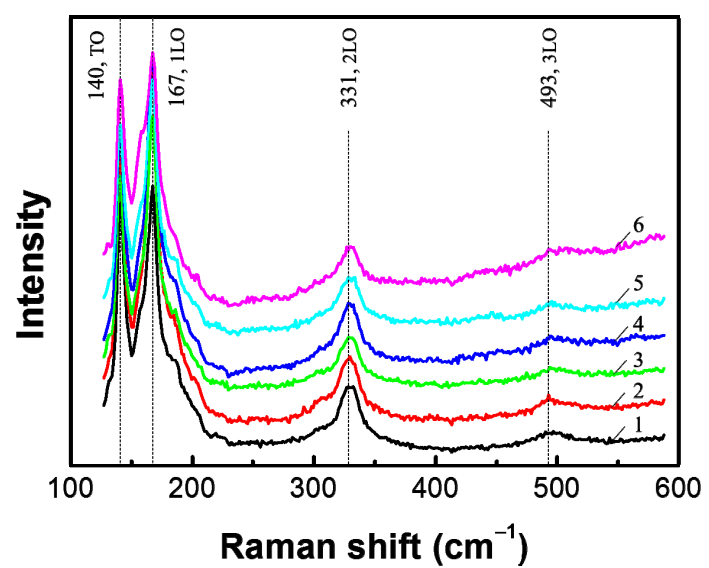

Figure 4 Raman scattering spectra of CdTe thin films and detailed presentation of TO and LO peaks for films deposited at different substrate temperatures $T_{s}$ and different deposition time: $350{ }^{\circ} \mathrm{C}-15 \min (1), 400{ }^{\circ} \mathrm{C}-15 \min (2), 450{ }^{\circ} \mathrm{C}-15 \min (3)$, $500{ }^{\circ} \mathrm{C}-15 \min (4), 550{ }^{\circ} \mathrm{C}-15 \min (5), 550{ }^{\circ} \mathrm{C}-30 \min (6)$ (TRIAX 550, $\lambda=514.5 \mathrm{~nm}$ ).



Figure 5 Raman spectra of thin CdTe film deposited at different substrate temperatures $T_{s}$, and different deposition time: 350 $15 \min (1), 400{ }^{\circ} \mathrm{C}-15 \min (2), 450{ }^{\circ} \mathrm{C}-15 \min (3), 500{ }^{\circ} \mathrm{C}-15$ $\min (4), 550{ }^{\circ} \mathrm{C}-15 \min (5), 550{ }^{\circ} \mathrm{C}-30 \min (6)$ (TRIAX 320, $\lambda=785 \mathrm{~nm})$.

In contrast to the Raman spectra of the $\mathrm{ZnSe}, \mathrm{ZnS}$, ZnTe films displacement the position of the peaks under changing of deposition regimes, associated with the occurrence of internal stresses in the layers, was not observed [29].

Also, the absence of Raman peaks associated with other compounds (oxides, nitrides, metal compounds, and carbon), indicates a high chemical purity of the investigated films. These results are in good agreement with the results obtained by the X-ray method (Fig. 2). 


\section{Conclusions}

Thin and thick CdTe films were obtained by thermal evaporation method. These films were investigated by Raman spectroscopy method. A number of intense lines at $140,167,190,271,332$ and $493 \mathrm{~cm}^{-1}$ were observed in the Raman spectra. These lines were interpreted according to reference data as TO $\left(140 \mathrm{~cm}^{-1}\right), 1 \mathrm{LO}\left(167 \mathrm{~cm}^{-1}\right), 2 \mathrm{LO}$ $\left(332 \mathrm{~cm}^{-1}\right)$, 3LO $\left(493 \mathrm{~cm}^{-1}\right)$ phonon modes and plasmonphonon mode $\left(190 \mathrm{~cm}^{-1}\right)$. The presences of several phonon replicas in the Raman spectra confirm high crystal quality of the samples.

Acknowledgements This work is supported by the Ukraine State Agency for the Science, Innovation, and Informatization and by the NRF grant funded by the MEST of Korea (2011-0019204) and by the Ministry of Education and Science of Ukraine.

\section{References}

[1] A. Owens and A. Peacock, Nucl. Instrum. Methods 531, 18 (2004).

[2] M. Bavdaz, A. Peacock, and A. Owens, Nucl. Instrum. Methods Phys. Res. 458, 123 (2001).

[3] Y. Eisen and A. Shor, J. Cryst. Growth 184, 1302 (1998).

[4] M. Yasuda, K. Watanabe, and A. Kai, Nucl. Sci. 56, 836 (2009).

[5] T. W. Kim, H. L. Park, and J. Y. Lee, Thin Solid Films 259 , 253 (2010)

[6] Q. Jiang, A. W. Brinkman, and B. J. Cantwell, J. Electron. Mater.; DOI 10.1007/s11664-009-0808-1 (2009).

[7] N. Lovergine, A. Cola, and P. Prete, Nucl. Instrum. Methods Phys. Res. A 458, 1 (2001).

[8] A. M. D. Ede, E. J. Morton, and P. De Antonis, Nucl. Instrum. Methods A 458, 7 (2001).

[9] B. K. Cha, K. Yang, and E. S. Cha, Nucl. Instrum. Methods A; DOI 10.1016/j.nima.2013.05.173 (2013).

[10] M. Niraula, K. Yasuda, and K. Takagi, J. Electron. Mater. 34, 815 (2010).

[11] R. Sorgenfrei, A. Zwerger, and C. Disch, J. Appl. Phys. 108, 094504 (2010).

[12] B. N. Zaveryuhin, Sh. A. Mirgasatov, and N. N. Zaveryuhina, Lett. J. Techn. Phys. 29, 80 (2003).

[13] T. M. Razykov, N. Amin, and M. A. Alghoul, J. Appl. Phys. 112, 023518 (2012).

[14] S. S. Islam, S. Rath, and K. P. Jain, Phys. Rev. B 46, 4982 (1992).

[15] Z. Bai J. Yang, and D. Wang, Appl. Phys. Lett. 99, 143502 (2011).

[16] M. Levy, J. Cryst. Growth 187, 367 (1998).

[17] V. V. Kosyak, D. I. Kurbatov, and M. M. Kolesnyk, J. Mater. Chem. Phys. 138, 731 (2013).

[18] G. F. Van der Voort, Metallography Principles and Practice (ASM International, New York, 1999), p.752.

[19] Selected powder diffraction data for education and training (search manual and data cards) (published by the International Centre for Diffraction Data, USA, 1988), p. 432.

[20] D. Park, D. Nam, and S. Jung, Thin Solid Films 519, 7386 (2011).

[21] V. V. Kosyak, A. S. Opanasyuk, P. M. Bukivskij, and Yu. P. Gnatenko, J. Cryst. Growth 312, 1726 (2010).
[22] C. J. Panchal, A. S. Opanasyuk, V. V. Kosyak et al., J. Nano Electron. Phys. 3(1), 274 (2011).

[23] P. M. Amirthara and F. H. Pollak, Appl. Phys. Lett. 45, 789 (1984).

[24] J. Contreras, J. Phys. D, Appl. Phys. 46, 245105 (2013).

[25] Z. C. Feng, S. Perkowitz, J. M. Wrobel, and J. J. Dubowski, Phys. Rev. B 39, 12997 (1989).

[26] W. J. Keeler and J. J. Dubowski, Can. J. Phys. 69, 255 (1991).

[27] M. J. Soares, J. C. Lopes, and M. C. Carmo, J. Phys. Status Solidi C 1, 278 (2004).

[28] N. Pahwa, A. D. Yadav, and S. K. Dubey, J. Nano-Electron. Phys. 3, 414 (2011).

[29] H. Cheong, D. Nam, M. M. Ivashchenko et al., Proc. Int. Conf. Nanomaterials: Applications and Properties (Ukraine, The Crimea) 1(3), 03TF21-1 (2012). 